\title{
Shaping news waves and constructing events: Iranian journalists' use of online platforms as sources of journalistic capital
}

new media \& society

(C) The Author(s) 2020

Article reuse guidelines: sagepub.com/journals-permissions DOI: 10.1 |77/|46/444820925457 journals.sagepub.com/home/nms

\author{
Banafsheh Ranji $\mathbb{1}$ \\ University of Oslo, Norway
}

\begin{abstract}
This article investigates the influence of online communications platforms on Iranian journalists' struggle for countering the restrictions, and achieving their journalistic ends. Based on 26 interviews with journalists working in the established media in Iran, it shows that social networking websites and mobile messaging applications are arenas of mobilization and leverage for journalists in this semi-authoritarian context. Online platforms function as sources of social and symbolic assets for journalists enabling them to make others see and think about an issue, and act on it, thus employ journalistic symbolic power. This article applies Bourdieu's concepts of doxa, social capital, symbolic capital and symbolic power to explain, why and under what circumstances certain journalistic online strategies become operative. The findings offer insights into how new media affect power relations between journalists and the forces that restrict their practices and offer potentials for relatively more journalistic autonomy in a controlled media environment.
\end{abstract}

\section{Keywords}

Doxa, interviews, Iran, journalists, mobilization, online communications platforms, social capital, symbolic capital, symbolic power

\section{Introduction}

Iranian media landscape includes different sectors with various forms of ownership and policies. While television and radio are under the direct control of the leader, the press

\footnotetext{
Corresponding author:

Banafsheh Ranji, Department of Media and Communication, University of Oslo, P.O. Box 1093, Blindern, 0317 Oslo, Norway.

Email: banafsheh.ranji@media.uio.no
} 
sector, including print and online, state-owned and privately owned media outlets, is a more dynamic domain and the ground for the factional struggle (Khiabany, 2008). In the restrictive media environment of Iran, the Internet, as well as satellite-based television and radio function as alternative channels of communication (Alikhah, 2008; SeyedEmami, 2008).

The Internet was introduced to Iran in 1993 (Rahimi, 2015). Internet World Stats (2019) reported that, in December 2018 , over $70 \%$ of Iran's population $(62,702,731)$ was Internet users, in a country with a population of around 82 million. Early online dissent activities started by the growth of conflict between the reformists and the conservatives, two main political factions, in the late 1990s, then the Internet began to be deemed a threat to the government (Khiabany, 2008; Rahimi, 2008). At the time, the crackdown on critical print publications intensified, and the Internet, in particular, blogs, became a domain of expression for various groupings, including journalists (Michaelsen, 2015). In the late 1990s, there was a growth in online journalism, which was created in response to the backlash against reformist print publications (Michaelsen, 2015).

Recently, there has been a rise in the use of social networking websites such as Instagram and Twitter, and mobile messaging applications, such as Telegram that was filtered in April 2018, with 40 million users in the country. Established news outlets have launched their official accounts and channels on Twitter, Instagram, and Telegram. Moreover, several online news outlets that are primarily based on social media and mobile messaging applications, namely, Telegram and Instagram, have emerged.

Despite the remarkable changes in the media ecology of Iran followed by the growing use of smartphones, social media, and mobile messaging applications, little is known about how and why Iranian journalists employ these platforms. This article redresses this gap by answering the following research question: How and for what purposes do Iranian journalists use online communications platforms?

Based on qualitative interviews with journalists working in Iran, this study, for the first time, establishes an understating of the implications and impacts of online communications platforms on Iranian journalists' struggle with the everyday restrictions. Using Bourdieu's theoretical concepts, it explains how new media influence the power relations between Iranian journalists and the forces that constrain their practices, mainly the political impositions, and how it has affected the dynamics of the flow of agenda in a semi-authoritarian context. Therefore, the second research question of this study is, how does the use of online platforms by Iranian journalists influence the flow of agenda in Iran?

\section{The Internet in politically restrictive contexts}

Central to the discussions about the Internet in restrictive settings is the function of the Internet as an alternative platform. Online alternative media is said to be a counterpoint to mainstream media providing the content that is censored and under-presented (e.g. Atton, 2002; Downing, 2001; Haas, 2004; Harcup, 2011). Simply put, by the use of alternative media, various actors have 'given themselves a voice' (Harcup, 2011: 19). Many studies have focused on online activism, citizen journalism, and the role of online forums in fostering public deliberation, mobilization, and interaction among like-minded 
actors in restrictive media settings (e.g. Diamond, 2010; Kyriakopoulou, 2011; Yang, 2003). While the existing literature has mainly focused on 'unprofessional' actors, such as activists, as the alternative media practitioners, this study links the discussion about the potentials of online platforms to journalistic power and autonomy in a restrictive media environment.

Several studies have identified new media as the alternative spaces for journalists to publish the stories that are unsayable in the established media in less democratic countries (e.g. Opgenhaffen and Scheerlinck, 2014; Skjerdal, 2011; Steele, 2009; Verweij and Van Noort, 2014). Much of the literature on this topic focuses on the Chinese context indicating that the Internet has taken the monopoly of traditional media over agenda-setting. The term 'agenda-setting' is defined as the power of shaping the media coverage in terms of what issue is covered (first-level agenda-setting), and how and through which attributes an issue is framed (second-level agendasetting) (Weimann and Brosius, 2017). It is thus the power of influencing what the public thinks about and how to think and thus constructing 'the social reality in the public's mind' (Luo, 2014: 1291). While the traditional agenda-setting theory focused on how political actors and ruling elites influence journalists, media coverage and thus the public agenda, recent research has discussed a more dynamic and complex process. With the rise of online spaces, researchers have theorized agenda-setting as a networked phenomenon in which various non-elite actors are involved (e.g. BarzilaiNahon, 2008; Meraz and Papacharissi, 2013). This literature has suggested that the Internet influences the flow of agenda in restrictive settings, and increases the chance of media coverage around sensitive issues (e.g. Luo, 2014; Sullivan, 2014; Wu et al., 2013). Hassid and Repnikova (2016: 887) suggest that micro-blogging as 'a backdoor way to bypass censorship' expands the boundaries of acceptable coverage and enables Chinese journalists to conduct 'investigative, critical, or politically sensitive reporting'. They argue that 'once a news item has been discussed enough online, many journalists reason it becomes publishable in the mainstream media regardless of sensitivity' (Hassid and Repnikova, 2016: 888). The existing materials pay little attention to the mechanism through which networking and mobilizing strategies of journalists become operative, a gap that this study redresses.

In the Iranian context, online platforms have taken the monopoly of the state over the means of communication (Abadpour and Anderson, 2013; Michaelsen, 2015; Sreberny and Khiabany, 2010). The existing research into the usage of the Internet in Iran has focused on blogs as an alternative public sphere to state-controlled media (e.g. Falasiri and Ghanavizi, 2015; Giacobino et al., 2014; Sreberny and Khiabany, 2010). Cyberspace is said to be a challenge to the Iranian state hegemony by offering platforms for 'critical discussion, tackling political and social taboos ranging from sex and politics to Islam and democracy' (Rahimi, 2008: 37). The Internet is thus identified as the 'new space of dissent' (Rahimi, 2008: 38), and 'the newest site of contestation' (Sreberny and Khiabany, 2010: 3). In addition, a considerable literature has emerged around the theme of social media during the 2009 post-election political upheaval (e.g. Faris and Rahimi, 2015; Kamalipour, 2010; Sadeghi Esfahlani, 2015; Wojcieszak and Smith, 2014). 
However, data from several studies suggest that we should avoid being overoptimistic about the potential of online platforms as 'free' spaces. Previous research has addressed particular challenges to the use of the Internet in less democratic environments such as surveillance by the authorities (e.g. Deibert and Rohozinski, 2010; Diamond, 2010; Kalathil and Boas, 2001). The Internet may be used by authorities to track journalists, particularly in countries such as Iran, China, Cuba and Nigeria where journalists get into trouble for what they publish online (e.g. Diamond, 2010; Goode, 2009; Kyriakopoulou, 2011). The Iranian state has attempted to control the Internet and to suppress the voices of dissidents through various tactics including surveillance, filtering, and disseminating hate speech (Faris and Rahimi, 2015; Kargar and Rauchfleisch, 2019). Rahimi (2015) addresses 'reactive' and 'proactive' control strategies of the Iranian state. Reactive methods refer to monitoring and disrupting the flow of information, for instance, by filtering websites and jamming certain satellite channels, and proactive strategies refer to the methods by which the Iranian state develops media technologies to be used for their own ends and to enforce their authority (Rahimi, 2015).

The literature has extensively focused on journalists' usage of blogs in Iran and has paid scant attention to the recent changes in the landscape of online communications platforms, a gap that is filled by this study. These studies suggest that due to the state control of media and the crackdown on critical newspapers in Iran, journalists have turned to cyberspace, in particular, blogs to continue writing (e.g. Giacobino et al., 2014; Sreberny and Khiabany, 2010). A survey-based report from Iranian bloggers by Giacobino et al. (2014) shows that in contrast to Iran's established media, blogs are open space 'for a range of voices including journalists' (p. 5), and resisting 'the hegemony of mainstream media, corporate ownership and state control of the media' (p. 30). Although much has been said about the Internet as an alternative platform in Iran that challenges the state, such expositions are unsatisfactory because they are often based on nonempirical methods. This study places the existing claims into examination based on interviews with Iranian journalists. Also, the studies on the role of online media in journalistic work in restrictive settings have tended to be descriptive. This article uses Bourdieu's conceptual toolkits namely social capital, symbolic capital, symbolic power, and doxa to explain why and under what circumstances certain journalistic online strategies materialize and become operative.

\section{Bourdieu's theoretical toolkits}

Drawing on Bourdieu's social theory, this research addresses what theoretical concepts explain the journalists' use of new media. It explores how online platforms function as sources of power (if at all) for Iranian journalists, and affect their strength in countering the restrictions, and in achieving their journalistic ends.

In Bourdieu's approach, the resources available to social agents that are accumulated over time are capital. The term capital, for Bourdieu (1986), equates with 'power' (p. 243). Hence, the different forms of capital (i.e. social, cultural and economic capitals) 'function as forms of power' (Swartz, 2013: 47). Social actors' capital gives them the advantage of access to specific benefits, and defines their strength and chance of success in their practices (Bourdieu, 1977). 
The concept of capital expresses the assumption that what actors can and cannot do is shaped by the resources in their hands. In this study, the concepts of social and symbolic capitals help us to look at the connection between the journalists' possessed resources in online communications platforms and their probabilities of success in making certain strategies operative.

Social capital includes 'the network of connections' (Bourdieu, 1986: 249) that could be mobilized. It is 'the aggregate of the actual or potential resources which are linked to possession of a durable network of more or less institutionalized relationships of mutual acquaintance and recognition - or, in other words, to membership in a group' (Bourdieu, 1986: 248). When social capital is socially recognized as 'legitimate competence', it converts to symbolic capital (Bourdieu, 1986: 245). Bourdieu (1986) refers to the name of 'a family, a class, or a tribe or of a school, a party' (p. 249), we may add the name of a 'profession', such as journalism, that could provide the members with symbolic capital, which is 'prestige and renown' (Bourdieu, 1977: 179).

Symbolic capital contributes to the formation of symbolic power, which is 'a power to construct reality' (Bourdieu, 1979: 79). This is the 'power of constituting the given through utterances, of making people see and believe, of confirming or transforming the vision of the world and thereby, action on the world and thus the world itself...' (Bourdieu, 1991: 170). For Bourdieu (1977), symbolic power is 'a major dimension of political power' (p. 165), and is exerted through 'symbolic systems' that are 'instruments of communication and knowledge' (Bourdieu, 1979: 81).

Thompson (1995) applies Bourdieu's notion of symbolic power to media, and defines it as 'capacity to intervene in the course of events, to influence the actions of others and indeed to create events, by means of the production and transmission of symbolic forms' (p. 17). Media power is thus an institution of symbolic power (Couldry, 2003). Mediated constructed reality is connected to the concept of 'agenda-setting' within media studies. Based on these theoretical perspectives, alternative media is a counterpoint to the agenda-setting and symbolic power of mainstream media (Atton, 2002; Couldry, 2003). Nevertheless, much less is known about what specific forms of capitals are at work in online communications spaces that shape the conditions for their implementation as alternative journalistic platforms, a gap that is filled by this study through the concepts of social and symbolic capitals. I also employ the concept of symbolic power to make meaning of the journalists' agenda behind their use of online platforms.

Another concept within Bourdieu's sociology that I apply in this study is doxa, which he defines as 'the universe of the tactical presuppositions that we accept as the natives of a certain society' (Bourdieu, 2005: 37). Doxa is the shared belief that is taken for granted among members of a specific field (Deer, 2012). Schultz (2007) applies the concept of doxa to journalism to discuss why and how Danish journalists make judgements about the newsworthiness of events. She refers to journalistic doxa as 'a set of professional beliefs which tend to appear as evident, natural and self-explaining norms of journalistic practice' (Schultz, 2007: 194). This study addresses how journalists' use of online platforms has influenced the doxa of the Iranian journalistic field concerning the sense of limit that the state and the dominant actors within the field, such as media managers, impose on journalists. 
Table I. List of the interviewees.

\begin{tabular}{|c|c|c|c|c|}
\hline Pseudonym & Age & Gender & Years in journalism & News beat \\
\hline Soren & 33 & male & 10 & Domestic politics \\
\hline Azin & 35 & female & 10 & Business and finance \\
\hline Omid & 34 & male & 12 & Domestic and international politics \\
\hline Simin & 32 & female & 13 & Domestic politics \\
\hline Ramin & 34 & male & 12 & Environment \\
\hline Amir & 60 & male & 34 & Society, art, and culture \\
\hline Feria & 27 & female & 7 & Society \\
\hline Tara & 29 & female & 9 & Society and politics \\
\hline Nadia & 33 & female & 9 & Domestic politics \\
\hline Farid & 32 & male & 14 & Society \\
\hline Kian & 36 & male & 16 & Society, politics \\
\hline Reza & 33 & male & 13 & Culture \\
\hline Hamid & 35 & male & 6 & Business and finance \\
\hline Milad & 29 & male & 9 & Domestic politics \\
\hline Samira & 30 & female & 9 & Domestic politics \\
\hline Nora & 37 & female & 17 & Business and finance \\
\hline Ali & 32 & male & 10 & International politics \\
\hline Hirad & 28 & male & 3 & Domestic and international politics \\
\hline Mina & 36 & female & 16 & Society \\
\hline Arman & 34 & male & 14 & Environment \\
\hline Faraz & 37 & male & 12 & Society \\
\hline Bita & 34 & female & 14 & Society \\
\hline Nahid & 29 & female & 9 & International politics, sports \\
\hline Azad & 36 & male & 18 & Labour news \\
\hline Nader & 28 & male & 12 & Law \\
\hline Aida & 35 & female & 15 & Domestic politics \\
\hline
\end{tabular}

\section{Method}

This article constructs an understanding of Iranian journalists' use of online platforms grounded in the actual lived experiences of those who engage in it. These data include 26 semi-structured and in-depth interviews with 14 male and 12 female journalists working in privately owned and state-owned national media outlets in Iran (please see Table 1). I conducted the interviews during autumn 2016 and winter 2018, and each interview took around 75 minutes. However, only a chosen part of the data is used for this research.

I initially relied on my network of journalistic contacts, and gradually expanded the sample through snowball sampling. I applied purposeful and maximal variation sampling in which 'diverse individuals are chosen who are expected to hold different perspectives on the central phenomenon' (Creswell and Clark, 2011: 147) and are 'information-rich' concerning the phenomenon under investigation (Patton, 1990: 169). This study focuses on how journalists use new media to circumvent the restrictions that they face in their everyday job. It practically means that there was a need to interview those journalists who identify a variety of constraints, ranging from political pressures to 
organization constraints, on their practices, and use online platforms for journalistic purposes. I therefore approached those journalists who, to a certain extent, hold a different point of view from the state's line and do not work in consonance with the centre of power.

To ensure maximal variation in the sample, I selected journalists with diverse backgrounds in terms of age, gender, ethnicity, years spent in journalism, news organizations, and news beats. They had the experience of working for various media channels with different forms of ownership and political orientations including television, radio, newspapers, news agencies, and news websites. Moreover, they had worked in different news beats including domestic and international politics, social, economic and cultural news beats. The most and the least experienced journalists had worked for 34 years and 3 years, respectively. The oldest journalist was 60 years, the youngest was 27 years old, and the majority of them were young adults. All the participants were Tehran based journalists because all national media outlets are located in Tehran.

To analyse the data, I used the thematic analysis method proposed by Braun and Clarke (2006). The role of thematic analysis was not to code features of the text in itself, but to try to track down the actual processes of the journalists' use of new media that are outside the text. Put differently, I adopted thematic analysis to identify themes that reflect mechanisms in the reality of the journalists' practices, not themes that are in the text per se. This study involves some specific ethical considerations, due to the sensitivity of the research topic and the potential risks to the interviewees. I therefore decided to use pseudonyms and anonymized direct quotations to conceal the identity of the interviewees and to ensure their safety, which is a crucial step in confidentiality and anonymity of the data. I also notified the university centre for research data and obtained informed consent from the interviewees.

\section{Findings}

The findings reveal that online communications platforms are the journalists' sources of higher leverage on an issue by involving more actors in talking about the issue and then acting on it. Some journalists mention that online platforms have granted them more autonomy in the face of not only political restrictions but also organizational constraints. Aida, who works in a privately owned newspaper, talks about Twitter: 'It increases your autonomy and gives you the hope that if you are not able to publish something in the news outlet where you work, you can do it on Twitter'. The journalists use social media, such as Facebook, Instagram, and Twitter (which is the most popular among the journalists), and mobile messaging applications, such as Telegram. They no longer use blogs, which have been at the centre of media scholars' attention for several years.

The journalists talk about imposing 'red lines' as a common practice through which the state actors try to influence journalism. In fact, the state tries to impose certain doxa, a sense of taken for granted limits, to the journalistic field. The interviews show that the connection of an issue with the core of state ideology and with the centre of power (mainly the leader) influences the level of sensitivity of the issue. For instance, topics such as religion, the compulsory hijab and sexual relationships outside marriage are outof-bounds due to their close connection to the state ideology. Investigative and critical 
reporting about certain institutions, such as the Judiciary and the Islamic Revolutionary Guard Corps are also sensitive topics because of their close connection to the centre of power. No external institution exerts pre-publication control on the press in Iran. However, the journalists talk about direct contacts, such as telephoned and written orders from the authorities to news organizations that command the boundaries of coverage from time to time. Some controversial topics are not entirely red lines, but have particular minefields that journalists should not touch such as ethnic and gender issues, poverty, child labour, and sex workers. These data suggest that organizational policies influence the chance of covering the issues with particular minefields. The journalists thus experience various levels of restrictions depending on the extent to which a news outlet and its dominant actors (owners and managers) are willing to move towards the red lines, rather than the type of ownership.

The journalists' sense of the limits on online platforms is different from what they experience in the established media. They adhere to certain red lines on the online platforms, however, these are at a different level if compared to the established media. These findings challenge the optimistic views in the literature about the Internet as an entirely free domain of expression. In fact, by using online media, the journalists can expand the boundaries of undiscussed topics (journalistic doxa) only to a certain point, and not entirely. Varieties of sensitive topics find their way onto online platforms, such as human rights issues, prisoners of conscience, gender and ethnic issues. Nevertheless, the topics closely connected to the fundamentals of the state remain unspoken, such as religion, the idea of vilāyat-i faqīh (the Guardianship of the Islamic Jurist), high ranked security agencies (e.g. the Islamic Revolutionary Guard Corps).

'Shaping news waves' is a recurrent term in the interviews, signifying that online platforms have facilitated the journalists in bringing issues to public attention and distributing content to a larger number of actors. The agenda behind trying to get a larger audience is making sensitive issues, publicly recognized, mobilizing action on the issues, employing symbolic power, thus constructing events. If it is risky for the journalists to pursue some line of enquiry on their own, they attempt to create public demand around the issue through online platforms. Soren, who works in a privately owned newspaper, says,

When we cannot cover an issue, we try to create public demand, which has become more common since the rise of social media, because activists and journalists can form online campaigns and make issues public. When the society inquires about an issue, the officials have to respond, and then we can cover the issue.

Drawing the public's attention creates public outrage, shapes enquiries regarding controversial issues, and pushes officials to respond. This consequently increases the possibility of media coverage of the content that was not previously allowed in the established media. In fact, when various actors and the public join the game, it is likely that the officials come to that game, although perhaps with a different approach. The journalists mention that in cases when an issue is widely discussed and gains social significance, or, to use Bourdieu's language, it is socially recognized and constructed as reality, media managers accept the coverage of the issue (which they previously rejected) so as not to fall behind the competition. The issue of Afghan refugees is a relatively 
controversial topic in Iran with specific minefields such as the way Iranian officials treat them. In the autumn of 2016, a report about a photo exhibition held by the local police in the city of Shiraz appeared on Iranian Students' News Agency, which is a conservative state-owned news agency. Among the photos, there were the photos of some arrested Afghan migrants, showing that the police had placed them in a space, similar to a sort of cage. The photos were selected and spread by activists, netizens and other actors on social media and sparked discussion. The following statement, from Simin, a journalist working in a state-owned news agency, shows how public outrage in social media around this issue resulted in a reaction from the authorities, and thus, made it possible to cover the issue in the established media:

\begin{abstract}
Sometimes the news agency I work at says that 'we are not working on an issue, they say this is our red line'. But when the issue is widely discussed in social media, and people talk about it, in order not to lag behind the competition, the news organization enters the game. For instance, some weeks ago the photos of some arrested Afghan migrants were spread on social media $[\ldots]$. The photos, and the bad behaviour of the police with the Afghans, received massive criticism from the public in the social media, something that I could not do in the news outlet where I work. As the objections increased, the police finally reacted, and the parliamentary representative for Shiraz reacted as well. Although the police denied having put them in a cage, and sort of justified their behaviour, at least they reacted, [and they are] an official body that is usually not responsive.
\end{abstract}

The online dissemination of content results in a wider distribution to various actors such as officials, activists, other journalists, netizens, and citizen journalists, who contribute to further dissemination through other channels of communications. Although Twitter is filtered, and access is possible through proxy servers, it is a favourite platform among the journalists because their posted content on Twitter circulates through other platforms, such as Telegram channels (thanks to the support of other actors). On many occasions, the content on journalists' social media pages is used in domestic and outsider news media, such as the Persian satellite TV channels, which reflects the flow of information from new media to traditional media.

While scholars have written about the online media as platforms from which to challenge the state in restrictive settings such as Iran (e.g. Rahimi, 2008; Sreberny and Khiabany, 2010), this study shows that it is also a domain from which to contest organizational restrictions. The journalists refer to the instrumentalization of the media outlets by various individuals and groups affiliated with external economic and political actors. An issue that the journalists consider 'newsworthy' may not be allowed to be covered. This is not only due to political constraints but also organizational policies and disagreement of other staff in the newsroom, particularly those in higher positions such as managing editors and media owners. New media thus facilitate journalists to push the boundaries of what is taken for granted as 'unsayable' by other actors within the journalistic field.

In May 2016, the payslips of top managers at a governmental insurance company were leaked to the media, which revealed that the managers were receiving generous salaries. The scandal damaged the reputation of Hassan Rouhani (the current president of Iran since 2013), who at the time was supported by the reformists. Omid, who works at a 
news agency affiliated with the reformists, says, 'The news agency where I work supports the presidential administration, I wanted to be critical about the payslip issue, but I could not publish it, then I used my social media'.

The journalists may obtain information, through their network of connections with officials that may not be officially stated, and thus not allowed to be published in the media. However, they may publish this information on social media. Tara, who works at the political desk of a privately owned newspaper, talks about the case of Sattar Beheshti. Sattar was an Iranian blogger who died in November 2012, several days after being arrested by the Iranian Cyber Police (FATA) for publishing critical content on his blog and Facebook. A police officer affiliated with FATA was convicted of killing Sattar and was sentenced to 3 years in jail (Iranian Students' News Agency, 2014). Tara talks about her use of social media in relation to this case:

A commission in the parliament investigated his murder, and they gained some information.

However, not all the information was allowed to be published, because it was not stated officially that there could be media coverage. We talked with MPs and knew about the information, but we were not allowed to publish it in the established media, as it had not been officially stated. We published some of this information on social media.

Other lines of evidence in the data further suggest that the Internet is not an entirely 'free' atmosphere. Media managers expect journalists to comply with the organizations' policies and interests, even in their personal social media accounts. There are cases in which the journalists were (or threatened to be) fired by media managers as the result of their online activities. Moreover, a few journalists in this study have been prosecuted for their posts on social media, some others have been asked about their online activities after being arrested for other reasons. The data show that state-affiliated actors have occasionally used social media for smear campaigns against journalists. The journalists are aware that they are under surveillance on the online media, and talk about the third eye between themselves and the audience. The following statement from Kian shows that a higher level of symbolic capital and a reputation on social media may put the journalists into political risk: 'A higher number of followers on social media and higher attention from the public in online media increases the chance of surveillance'. There have also been cases in which the authorities contacted news organizations and ordered media managers to stop collaborating with a specific journalist because of their online activities, for instance, the content that they have published on Twitter, and thus, the news organization has fired them at the authorities' request.

\section{Online platforms as sources of social and symbolic capitals}

This study suggests that the journalists' social media accounts and the related networks are forms of social and symbolic capitals. During the process of publicizing issues, the journalists use their network of connections and their renown to have leverage and influence people's minds. The journalists usually plan to 'shape news waves' collectively with other journalists.

In this process, apart from mobilizing their fellow journalists (their internal social capital), the journalists become involved in online campaigns, together with a range of 
actors from activists to the ordinary public to make a variety of actors see, and think about an issue that is normally unspoken in the established media. In fact, they attempt to employ symbolic power. The following statement from Feria shows how the journalists attempt to construct reality from their particular points of view by using social media:

You create an event [through online communications platforms]. I mean something takes place, others do not think that it is an event. You work on it, and it becomes an event, others act on it, talk about it, you create wave and flow.

Workers' rights and the coverage of their precarious living conditions and their strikes have been relatively controversial issues in Iran. In May 2016, 17 workers at a gold mine in Iran, Agh Dare, were flogged following a court order that was based on a complaint by the employer because they participated in a strike, and each worker received between 30 and 100 lashes. This issue was discussed on social media and sparked public outrage. Hamid, working for a state-owned newspaper, says,

The issue spread through the Internet and this enabled media coverage. It is very important that an issue becomes a 'subject'. [Here, a subject means a topic of discussion]. For this, the issue needs to be raised widely. It was the Internet that shaped a subject from Agh Dare; otherwise, it would have been neglected like many other happenings.

Employing journalistic symbolic power is not only about constructing events (first-level agenda-setting), but also influencing the direction in which events develop (second-level agenda-setting). Milad talks about his use of Twitter: 'Something is happening, and you see that a certain climate is being shaped around it, you feel the climate should be changed, intensified or weakened'.

To be able to mobilize various actors, the journalists need to be recognized as reliable and legitimate news sources, and gain symbolic capital. They express their satisfaction with the fact that social media, particularly Twitter, have facilitated them in becoming publicly known as a member of 'trustworthy reference groups', and as a journalist with a specific news beat. This results in the accumulation of symbolic capital in the form of recognized cultural capital. Being recognized as a journalist with competence and knowledge in a specific area, gives them higher chances of success in getting their social media content to be distributed by other well-known journalists and news outlets.

Contrary to expectations, the journalists avoid using anonymous identities and show the title 'journalist' on their social media pages, which, as they think, enables them to position themselves in a relationship of trust with the audience, and influence them. Faraz says, 'You cannot have social influence with an anonymous identity'. Bourdieu (1991) says that by acting and speaking on behalf of a legitimate group (a group that possesses symbolic capital), agents can claim that 'they are not acting on their own name and under their own authority'; thus, it gives them legitimacy (p. 75).

Interaction with the audience plays a role in building a trusting relationship, and in preserving journalistic symbolic capital. Hamid says, 'All my concern about my online activities is being influential. Having influence is not achievable without interaction, [...] being responsive shapes my status. How I am recognized on social media and not losing my audience are important to me'. Previously, the interaction was primarily possible through receiving phone calls from the audience at their offices in news 
organizations. In media that offer the possibility of the audience commenting, such as news websites, the comments are controlled and censored before being publicly published, and the journalists usually do not have access to the original comments.

Online platforms have also assisted the journalists' linkages to unofficial news sources, and the ordinary public who are involved in, or affected by, an event. This has facilitated them in communicating with local people in those areas that they cannot reach due to the lack of financial resources or security issues. A journalist talks about his connections with workers around the country through Telegram. The workers keep him informed about events, such as workers' strikes and protests, while face-to-face communication with the workers might pose safety risks to the journalist.

Despite the arguments in the literature about journalists' concerns about the rise of citizen journalism, the journalists in this study express their satisfaction with citizen journalism. They mention that the new media has taken their monopoly over the news, and has made them rethink their roles. However, it is significant to them that in a country with limited freedom of expression, different actors have access to online platforms, which has facilitated discussion about topics that are often unspoken in the established media. Ramin, working for a privately owned newspaper, says,

Social networking websites have made issues public. They have taken the buttons for sending news from journalists and editors, and have given them to the people. In a restricted society that needs public awareness to take action for change, nothing is better than people managing the button for sending news.

Scholars (e.g. Carlson, 2007; Obijiofor and Hanusch, 2011) have argued that new media challenge the professional aspects of journalism, such as credibility. However, there is evidence in this study that the journalists' use of online platforms may result in more professionalism to maintain their recognition and symbolic capital. The journalists argue that they attempt to perform professionally because they are under the scrutiny and criticism of various actors, including the public, other journalists, politicians, and activists. Amir talks about the influence of social media on his practices: 'You are constantly under the criticism of the audience, and you receive feedback that makes you revise your work'. The data show that it is the sense of social influence that drives the journalists to use social media rather than monetary profits and accumulation of economic capital. In addition, publishing critical content may result in the dismissal of journalists and their unemployment, and thus precarious living conditions. However, a journalist talks about the involvement of a few journalists in financially beneficial activities, such as the public relations sector, which is the result of their recognition through online platforms. He sees this issue in relation to the economic precariousness in which Iranian journalists work, and the fact that some journalists have other jobs to be able to support themselves financially.

\section{Discussion and conclusion}

This study provides insights into the dynamics of the flow of agenda within new media ecology in a semi-authoritarian context. It sheds light on how Iranian journalists attempt to set the public agenda in light of the new potentials of the Internet, in a context where 
the state attempts to dominate the agenda-setting power. While it is often discussed that in politically restrictive contexts, those in politics shape the agenda of journalists and dominate the public discourse, this study reveals that journalists also influence the agenda of political actors, which is facilitated by online platforms.

This article suggests that even in the contexts of a strongly censored media, online platforms change the power relations between journalists and political actors as well as the dominant actors within the journalistic field. This offers possibilities for relatively more journalistic autonomy. There has been an ongoing contestation between the journalistic field and the political field over constructing reality or as Castells (2007) says, 'the battle over the minds of the people' (p. 238). In this struggle, online 'socialized communication' as the domain of 'the social production of meaning' (Castells, 2007: 239) functions as a source of journalistic assets through which journalists can set the agenda and exert symbolic power. Put simply, the Internet opens up the possibility for journalists to define reality from their own perspectives, which reflects the old arguments about the role of journalists as gatekeepers in constructing social reality. Online spaces are thus new tools for an old struggle: the struggle over exerting symbolic power.

Aside from being an alternative publishing space, this study further shows online media are also arenas for mobilization and leverage, and accumulation of journalistic social and symbolic capitals in restrictive settings. Online platforms improve networking opportunities of journalists, which results in engagement and collaboration among a variety of actors to act on controversial issues that are normally unspoken in the official media. The 'decentralized' nature of communication on the Internet, allows a large number of actors to speak on an issue and thus provides an atmosphere of discussion with less centralized control (Tang and Sampson, 2012; Yang, 2003), which consequently protect journalists against the possible risks of securitizing sensitive issues. In fact, as Tang and Sampson (2012) argue, mobilization of public opinion opens leeway for more legitimate coverage of sensitive issues in the established media, and amplifies 'pressure on government officials and offers the potential for administrative intervention' (p. 468). This consequently enables journalists to influence socio-political processes and expand not only the limits of journalistic doxa but also the public discourse.

The literature has emphasized on what Castells (2007: 248) terms 'counter-power' dimension of the new communications spaces, which is 'the capacity by social actors to challenge and eventually change the power relations institutionalized in society'. However, power is relational, and as Foucault (1978: 93) says 'power is everywhere' and 'is produced from one moment to the next, at every point, or rather in every relation from one point to another'. The power to construct reality is also an object of struggle among 'various social groups with different strengths' (Bourdieu, 1991: 166). New media provide 'counter-power' possibilities for journalists in relation to political actors, while the journalists possess social, cultural and symbolic capitals, and exert their symbolic power over a range of actors.

The boundaries of the topics that are constructed online as a symbolic product are limited as the fundamentals of state ideology remain largely untouched, and journalists tend to work on issues that allow leeway for discussion in the established media. The journalists' use of new media, therefore, does not challenge the whole political system. Through the concept of doxa, this study shows that the sense of limits that are imposed 
by the political field and other actors within the journalistic field are not taken for granted by the journalist. However, journalists can push the limits and expand the boundaries of journalistic doxa and the public discourse only to a certain point, and this challenges the optimistic views about the 'liberatory' capacity of online spaces. Nevertheless, the relative 'counter-power' capacity of online networks offers journalists 'the testing of a potential erosion of state control and, with such small steps, the exercise of counter-power may ultimately produce more long-term and significant socio-political change' (Tang and Sampson, 2012: 469).

Bourdieu's concepts of social and symbolic capitals have allowed exploring the sources of symbolic power in the new media environment, and explaining the logic of the operation of networking and mobilizing strategies of journalists. This research suggests that the journalists' chances of success in following certain controversial issues depend on their level of leverage through online platforms, that is, the power to influence other actors, to activate them, to bring them into the game, and to reach the outcome they want. The symbolic power of journalists through online platforms can thus materialize only in relation to certain issues, and in certain conditions depending on the journalists' social and symbolic assets. In fact, in a networked context, the status of journalists as elites is contingent 'on the networked actions of the nonelite' (Meraz and Papacharissi, 2013: 23). This issue reflects 'a new symbiotic interrelationship between the influential and the ordinary in a manner that elevates the actions of non-elites as active participants in the realization of what is newsworthy' (Meraz and Papacharissi, 2013: 23).

The discussions about the role of the online spaces in facilitating public debate around sensitive issues pay little attention to why certain topics, and not others, are discussed and mobilization is shaped around them. In fact, there is a tendency to look at online platforms as spaces that are naturally endowed with public debate. However, as this study shows, a topic cannot exist and develop into the subject of discussion out of nothing or, as Bourdieu (1991) says, 'ex nihilo', but it needs to be constructed as a symbolic object influencing people's minds. As Tang and Yang (2011) argue, 'what the Internet facilitates is producing follow-up discourse once a powerful symbol has appeared' (p. 687). This study suggests that a symbolic product is likely to be constructed when social and symbolic capitals are present, thereby 'with access to the Internet and inspired by the symbol, people produce follow-up discourses, which in turn help the symbol to create a symbolic network and take root in the society quickly and deeply' (Tang and Yang, 2011: 687).

Given the small sample size of 26 journalists, the generalizability of the results to all Iranian journalists is subject to certain limitations. However, this study is one of the rare studies to contribute to our understanding of a significant section of the Iranian journalistic field who use online platforms in pursuit of relatively more journalistic autonomy in the face of restrictions. The qualitative interviews offered insights into how journalists strive to influence a variety of actors ranging from politicians to the ordinary public, and showed that agenda-setting dynamics is not a one-dimensional and static process in the digital era even in the most obvious restrictive settings. In light of the recent theoretical perspectives on gatekeeping in a networked environment (e.g. Meraz and Papacharissi, 2013; Weimann and Brosius, 2017), further research could conduct multi-methodological studies to develop a more comprehensive picture of the patterns of 
communications in online spaces in the restrictive context of Iran. For instance, in future investigations, it is useful to address how diverse actors in various positions with different agendas (e.g. activist agenda) shape the public discourse in the face of the state control in Iran.

\section{Funding}

The author(s) received no financial support for the research, authorship, and/or publication of this article.

\section{ORCID iD}

Banafsheh Ranji (D) https://orcid.org/0000-0002-0679-4193

\section{References}

Abadpour A and Anderson C (2013) Fights, Adapts, Accepts: Archetypes of Iranian Internet Use. Iran Media Program. Available at: http://abadpour.com/files/pdf/fightsadaptsaccepts.pdf

Alikhah F (2008) The politics of satellite television in Iran. In: Semati M (ed.) Media, Culture and Society in Iran: Living with Globalization and the Islamic State. London: Routledge, pp. 94-110.

Atton C (2002) Alternative Media. London: SAGE.

Barzilai-Nahon K (2008) Toward a theory of network gatekeeping: a framework for exploring information control. Journal of the American Society for Information Science and Technology 59(9): 1493-1512.

Bourdieu P (1977) Outline of a Theory of Practice. Cambridge: Cambridge University Press.

Bourdieu P (1979) Symbolic power. Critique of Anthropology 4(13-14): 77-85.

Bourdieu P (1986) The forms of capital. In: Richardson JG (ed.) Handbook of Theory and Research for the Sociology of Education. New York: Greenwood Publishing Group, pp. 241-258.

Bourdieu P (1991) Language and Symbolic Power. Cambridge: Polity.

Bourdieu P (2005) The political field, the social science field, and the journalistic field. In: Benson R and Neveu E (eds) Bourdieu and the Journalistic Field. Cambridge: Polity, pp. 29-47.

Braun V and Clarke V (2006) Using thematic analysis in psychology. Qualitative Research in Psychology 3(2): 77-101.

Carlson M (2007) Blogs and journalistic authority. Journalism Studies 8(2): 264-279.

Castells M (2007) Communication, power and counter-power in the network society. International Journal of Communication 1(1): 238-266.

Couldry N (2003) Media meta-capital: extending the range of Bourdieu's field theory. Theory and Society 32(5): 653-677.

Creswell JW and Clark V (2011) Designing and Conducting Mixed Methods Research. 2nd ed. Los Angeles, CA: SAGE.

Deer C (2012) Doxa. In: Grenfell M (ed.) Pierre Bourdieu: Key Concepts. London: Routledge, pp. 114-125.

Deibert R and Rohozinski R (2010) Liberation vs. control: the future of cyberspace. Journal of Democracy 21: 43-57.

Diamond L (2010) Liberation technology. Journal of Democracy 21(3): 69-83.

Downing JDH (2001) Radical Media: Rebellious Communication and Social Movements. Thousand Oaks, CA: SAGE. 
Falasiri A and Ghanavizi N (2015) The Persian blogosphere in dissent. In: Faris DM and Rahimi B (eds) Social Media in Iran: Politics and Society after 2009. Albany, NY: SUNY Press, pp. 123-136.

Faris DM and Rahimi B (2015) Introduction. In: Faris DM and Rahimi B (eds) Social Media in Iran: Politics and Society after 2009. Albany, NY: SUNY Press, pp.1-15.

Foucault M (1978) The History of Sexuality. New York: Pantheon Books.

Giacobino L, Abadpour A, Anderson C, et al. (2014) Whither Blogestan: Evaluating Shifts in Persian Cyberspace. Iran Media Program. Available at: http://repository.upenn.edu/iranme diaprogram $/ 12$

Goode L (2009) Social news, citizen journalism and democracy. New Media \& Society 11(8): $1287-1305$.

Haas T (2004) Alternative media, public journalism and the pursuit of democratization. Journalism Studies 5(1): 115-121.

Harcup T (2011) Alternative journalism as active citizenship. Journalism 12(1): 15-31.

Hassid J and Repnikova M (2016) Why Chinese print journalists embrace the Internet. Journalism 17(7): 882-898.

Internet World Stats (2019) Internet usage in the Middle East. Available at: https://www.internet worldstats.com/middle.htm\#ir

Iranian Students' News Agency (2014) Si sāl ḥabs, mujāzāt-i qātil-i Satar Beheshti [Three years imprisonment, punishment for Satar Beheshti's assassin]. Available at: https://www.isna.ir/ news/93051607556

Kalathil S and Boas TC (2001) The Internet and state control in authoritarian regimes: China, Cuba and the counterrevolution. First Monday 6(8). Available at: https://firstmonday.org/article/ view/876/785

Kamalipour YR (ed.) (2010) Media, Power, and Politics in the Digital Age: The 2009 Presidential Election Uprising in Iran. London: Rowman \& Littlefield.

Kargar S and Rauchfleisch A (2019) State-aligned trolling in Iran and the double-edged affordances of Instagram. New Media \& Society 21: 1506-1527.

Khiabany G (2008) The Iranian press, state, and civil society. In: Semati M (ed.) Media, Culture and Society in Iran: Living with Globalization and the Islamic State. London: Routledge, pp. 17-36.

Kyriakopoulou K (2011) Authoritarian states and internet social media: instruments of democratization or instruments of control? Human Affairs 21: 18-26.

Luo Y (2014) The Internet and agenda setting in China: the influence of online public opinion on media coverage and government policy. International Journal of Communication 8(24): 1289-1312.

Meraz S and Papacharissi Z (2013) Networked gatekeeping and networked framing on \#Egypt. The International Journal of Press/Politics 18(2): 138-166.

Michaelsen M (2015) The politics of online journalism in Iran. In: Faris DM and Rahimi B (eds) Social Media in Iran: Politics and Society after 2009. Albany, NY: SUNY Press, pp. 101-122.

Obijiofor L and Hanusch F (2011) Journalism Across Cultures: An Introduction. Abingdon: Palgrave Macmillan.

Opgenhaffen M and Scheerlinck H (2014) Social media guidelines for journalists. Journalism Practice 8(6): 726-741.

Patton MQ (1990) Qualitative Evaluation and Research Methods. 2nd ed. Thousand Oaks, CA: SAGE.

Rahimi B (2008) The politics of the Internet in Iran. In: Semati M (ed.) Media, Culture and Society in Iran: Living with Globalization and the Islamic State. London: Routledge, pp. 37-56. 
Rahimi B (2015) Internet censorship in Rouhani's Iran: the 'wooden sword'. Asian Politics \& Policy 7(2): 336-341.

Sadeghi Esfahlani M (2015) The politics and anti-politics of Facebook in context of the Iranian 2009 presidential elections and beyond. In: Faris DM and Rahimi B (eds) Social Media in Iran: Politics and Society after 2009. New York: SUNY Press, pp. 137-163.

Schultz I (2007) The journalistic gut feeling. Journalism Practice 1(2): 190-207.

Seyed-Emami K (2008) Youth, politics, and media habits in Iran. In: Semati M (ed.) Media, Culture and Society in Iran: Living with Globalization and the Islamic State. London: Routledge, pp. 57-68.

Skjerdal TS (2011) Journalists or activists? Self-identity in the Ethiopian diaspora online community. Journalism 12(6): 727-744.

Sreberny A and Khiabany G (2010) Blogistan: The Internet and Politics in Iran. London: I. B. Tauris.

Steele J (2009) Professionalism online: how Malaysiakini challenges authoritarianism. The International Journal of Press/Politics 14: 91-111.

Sullivan J (2014) China's Weibo: is faster different? New Media \& Society 16: 24-37.

Swartz DL (2013) Symbolic Power, Politics, and Intellectuals: The Political Sociology of Pierre Bourdieu. Chicago, IL: University of Chicago Press.

Tang L and Sampson H (2012) The interaction between mass media and the Internet in nondemocratic states: the case of China. Media, Culture \& Society 34(4): 457-471.

Tang L and Yang P (2011) Symbolic power and the Internet: the power of a 'horse'. Media, Culture \& Society 33(5): 675-691.

Thompson JB (1995) The Media and Modernity: A Social Theory of the Media. Stanford, CA: Stanford University Press.

Verweij P and Van Noort E (2014) Journalists' Twitter networks, public debates and relationships in South Africa. Digital Journalism 2(1): 98-114.

Weimann G and Brosius HB (2017) Redirecting the agenda. The Agenda Setting Journal 1(1): 63-102.

Wojcieszak M and Smith B (2014) Will politics be tweeted? New media use by Iranian youth in 2011. New Media \& Society 16: 91-109.

Wu Y, Atkin D, Lau TY, et al. (2013) Agenda setting and micro-blog use: an analysis of the relationship between Sina Weibo and newspaper agendas in China. The Journal of Social Media in Society 2(2): 8-25.

Yang G (2003) The Internet and civil society in China: a preliminary assessment. Journal of Contemporary China 12: 453-475.

\section{Author biography}

Banafsheh Ranji holds a PhD from the University of Oslo. She is currently in a research and teaching position in the department of Media and Communication at the University of Oslo. Her research focuses on the sociology of media and journalism in politically restrictive contexts. 